\title{
ESCOLARIZAÇÃO DAS ELITES NA PRODUÇÃO ACADÊMICA DO BRASIL
}

\author{
Fábio Ribeiro Machado ${ }^{1}$ \\ Luciana Siqueira Walter ${ }^{2}$
}

\begin{abstract}
Resumo: A escola representa um espaço no qual serão mobilizados valores comuns a um grupo. Assim, a escolha da escola na qual os descendentes irão estudar significa escolher quais valores serão compartilhados por eles e entre que grupo de indivíduos. Neste caso, a escola não funciona como um espaço democratizante e sim como um local onde estes elementos serão compartilhados, alimentados e reproduzidos. Neste trabalho nos propomos a construir um panorama sobre escolarização das elites a partir das dissertações de mestrado e teses de doutoramento produzidos no Brasil cadastrados na plataforma Sucupira da Capes entre os anos 2000 e 2016 e os períodos Qualis A1 e A2 da área de educação no mesmo período. A análise compreende os resultados de levantamento de dados por palavra chave de 6 dissertações, 48 periódicos Qualis A1 e 77 periódicos Qualis A2. Assim é possível verificar as temáticas e as abordagens que vem sendo utilizadas nas pós-graduações do país agrupando-as por região e área do conhecimento. Este trabalho é a primeira parte de uma pesquisa que pretende entender como a escolarização dos herdeiros das elites atua na reprodução dos seus valores, espaços e privilégios e qual a importância desta nas suas trajetórias.
\end{abstract}

Palavras-Chaves: elites, escolarização, abordagens temáticas, trajetórias.

\section{THE SCHOOLING OF ELITES IN THE ACADEMIC PRODUCTION OF BRAZIL}

\begin{abstract}
The school represents a space in which values common to a group will be mobilized. Thus the choice of the school in which the descendants will study means to choose which values will be shared by them and among which group of individuals. In this case, the school does not function as a democratizing space, but as a place where these elements will be shared, fed and reproduced. In this work we propose to construct a panorama about schooling of the elites from the master dissertations and doctoral theses produced in Brazil registered in the platform Sucupira of Capes between the years 2000 and 2016 and the periods Qualis A1 and A2 of the area of education in the same period. The analysis comprises the results of a key word data collection from 6 dissertations, 48 Qualis A1 journals and 77 Qualis A2 journals. Thus, it is possible to verify the themes and approaches that are being used in the country's postgraduate studies by grouping them by region and area of knowledge. This work is the first part of a research that intends to understand how the schooling of the heirs of the elites acts in the reproduction of their values, spaces and privileges and how important it is in their trajectories.
\end{abstract}

Keywords: elites, schooling, thematic approaches, trajectories.

- Enviado em 15/07/2017

- Aprovado em 28/07/2017

\footnotetext{
${ }^{1}$ Mestre em Ciência Política pela Universidade Federal de Pernambuco (UFPE). Professor de Ciência Política da Unidade Acadêmica de Ciências Sociais da Universidade Federal de Campina Grande (UFCG). E-mail: rmfabio1@ hotmail.com

${ }^{2}$ Graduada em História (UFPE). Professora de História da Rede Estadual da Paraíba. E-mail: uciana.walter@gmail.com

Uma versão preliminar desse texto foi apresentada no $18^{\circ}$ Congresso Brasileiro de Sociologia. Que Sociologia fazemos? Interfaces com contextos locais, nacionais e globais. 26 a 29 de julho de 2017. Centro de Convenções Ulysses Guimarães, Brasília/DF
} 


\section{Introdução}

A escola representa um espaço no qual são mobilizados valores comuns a um grupo inclusive no caso dos grupos pertencem às classes dominantes. Assim, a escolha da escola na qual os descendentes irão estudar significa escolher quais valores serão compartilhados por eles e entre que grupo de indivíduos. Neste caso, a escola não funciona como um espaço democratizante e sim como um local onde estes elementos serão compartilhados, alimentados e reproduzidos.

Para compreender os processos de constituição das elites enquanto classe dominante, Ana Maria Almeida e Maria Alice Nogueira (2003), apontam para a conveniência de se pensar como as elites constroem suas visões de mundo, as maneiras e por meio de que processos esses grupos se desenvolvem, como eles pensam sobre si mesmos e sobre os outros, a fim de refletirmos sobre os modos de socialização escolar dos jovens herdeiros das famílias privilegiadas. Pois é na escola que se dá a construção e mobilização desses saberes e valores que vão constituir os habitus e os capitais $^{3}$ compartilhados por esses grupos. São estes grupos que participam das disputas de poder e dominação na sociedade contemporânea. Segundo José Marciano Monteiro,

essa lógica de dominação que predomina no mundo prático, tende a se reproduzir por meio de herdeiros - indivíduos que herdam o patrimônio econômico e o patrimônio simbólico familiar do grupo. E, para isso, a escola - instituição de reprodução da cultura legítima - e o conhecimento do herdeiro das regras do jogo político se tornam fundamentais. Toda via, a herança por si só não é elemento possível para garantir aos herdeiros a permanência no campo político. Não é o "sobrenome' que garantirá aos herdeiros a permanência no polo dominante, no campo de lutas, embora seja um capital simbólico extremamente importante" (2017, p.75).

Sendo assim, as relações de poder se constroem em forma de teia, misturando o público e o privado, incorporando as redes de relação familiar e parental à estruturação do Estado. Nesse contexto, ao considerar o conceito de família patriarcal como essencial à compreensão histórica e social do Brasil é difícil não pensar de forma estruturante também as nossas relações políticas, dado a forma como vemos se repetir ao longo dos anos, os nomes das grandes famílias pertencentes às classes dominantes imbricadas com as estruturas de poder. Nessa perspectiva "o habitus advindo e constituído no seio das famílias políticas imbrica-se, soma-se, ao habitus escolar constituído nessas

\footnotetext{
${ }^{3}$ Os conceitos de habitus e capital são utilizados como desenvolvidos por Pierre Bourdieu.
} 
instituições para a atuação no mundo da política. Constrói-se, assim, o habitus de classe referente às elites políticas e econômicas do Estado que formam a classe dominante.” (MONTEIRO, 2017. P. 62)

A necessidade de legitimar a colocação em posições privilegiadas dos herdeiros, pois pertencem à determinada família dos grupos dominantes não garante por si só a posição de pertencimento ao lugar de dominação. É preciso ter domínio do jogo de poder e ser capaz de demonstrar as competências necessárias correspondentes para tal. Dessa forma a formação universitária, mas também a educação básica será de extrema importância na incorporação dos habitus e capitais social e cultural. Esta formação que compõe o conjunto de saberes que são necessários à manutenção e a boa vivência através dos valores e visão de mundo compartilhado entre os grupos de elite passa pela educação escolar.

É importante destacar que esta é a primeira parte de uma pesquisa que pretende entender como a escolarização dos herdeiros das elites atuam na reprodução dos seus valores, espaços e privilégios e qual a importância desta nas suas trajetórias. Trata-se, portanto, de um trabalho inicial, de caráter exploratório e bastante descritivo. Estes dados e resultados preliminares serão aprofundados e devidamente discutidos no decorrer da pesquisa.

Neste Trabalho nos propomos a esboçar um perfil dos estudos sobre a escolarização das elites a partir das dissertações de mestrado produzidos no Brasil e cadastrados na Plataforma Sucupira da Capes entre os anos 2000 e 2016 e os periódicos Qualis A1 e A2 da área de educação no mesmo período. A análise compreende os resultados de levantamento de dados por palavra chave de 05 dissertações, 48 periódicos Qualis A1 e 77 periódicos Qualis A2, totalizando 125 periódicos analisados num recorte de 16 anos de produção.

Além dos sítios eletrônicos dos próprios periódicos, foi utilizado o banco de dados do Scielo (www.scielo.com) como banco de pesquisa. Como opção metodológica buscou-se os artigos pelas palavras chaves "escolarização das elites", “escolarização" e “elite”. Durante o levantamento dos dados foram encontrados 07 artigos pertinentes ao tema nos periódicos Qualis A1 e 02 artigos pertinentes ao tema nos periódicos Qualis A2. 


\section{As dissertações de mestrado catalogadas pela CAPES e o tema da escolarização das elites}

O tema da escolarização das elites comumente é desenvolvido na área da Sociologia da Educação. A despeito do aumento recente de estudos sobre esse tema, e de sua importância por abordar pontos centrais sobre o funcionamento das nossas sociedades, são poucos autores e/ou grupos de pesquisa no Brasil que tem contribuído para uma formulação teórico-metodológica que concorra para o avanço dos estudos dessa temática. O lugar discreto ocupado por esses estudos deve-se, em grande parte, ao fato de que, por razões legítimas e mesmo compreensíveis, a predileção dos cientistas sociais recaiu sobre a escolaridade das camadas populares (Almeida \& Nogueira, 2003: 7).

O resultado a que esse trabalho chegou após o levantamento das dissertações de mestrado (nenhuma tese de doutorado foi encontrada nesse levantamento) cadastradas na plataforma Sucupira da Capes entre os anos 2000 e 2016, demonstra que o tema da escolarização das elites continua na penumbra. Isto porque nos últimos dezesseis anos nenhuma tese de doutorado foi encontrada tratando desse tema, e, apenas cinco dissertações constam daquele banco de dados.

Assim mesmo, como assevera Almeida \& Nogueira (2003: 7-8) os estudos sobre a "escolarização das elites" aborda pontos centrais sobre o funcionamento das nossas sociedades, e nos permite verificar como são formados aqueles e aquelas para quem estão reservadas as mais altas posições sociais. Além disso, podemos observar a maneira como os jovens aprendem a administrar relações e como convertem diferenças sociais em diferenças de estilo de vida. Esses estudos nos ajudam também a compreender melhor o funcionamento dos sistemas de ensino em nossas sociedades, esclarecendo de forma mais explícita, a maneira como são produzidos e circulam os critérios de excelência escolar utilizados para julgar o conjunto de alunos. Dessa forma, para quem deseja compreender os processos de construção social das desigualdades educativas, o tema da escolarização das elites é de fundamental importância.

Questões do tipo: qual a natureza das abordagens utilizadas nas dissertações defendidas nos cursos de pós-graduação no Brasil, e quais os conteúdos que elas apresentam sobre as elites e seus processos de escolarização, nortearam esse trabalho ora apresentado. Porém, antes de procedermos a análise resumida desse conjunto de dissertações, tomamos a iniciativa de reproduzirmos seus respectivos resumos a seguir. 
$\checkmark$ Quadro 01 - Resumo da dissertação ${ }^{4}$

\begin{tabular}{|c|c|}
\hline Rest & $\begin{array}{l}\text { social e escolar de jovens pretendentes a dirigentes. Sorocaba } \\
\text { 2005, 115p. (Dissertação de Mestrado) Mestrado e Educação, } \\
\text { Universidade de Sorocaba. }\end{array}$ \\
\hline \multicolumn{2}{|c|}{ 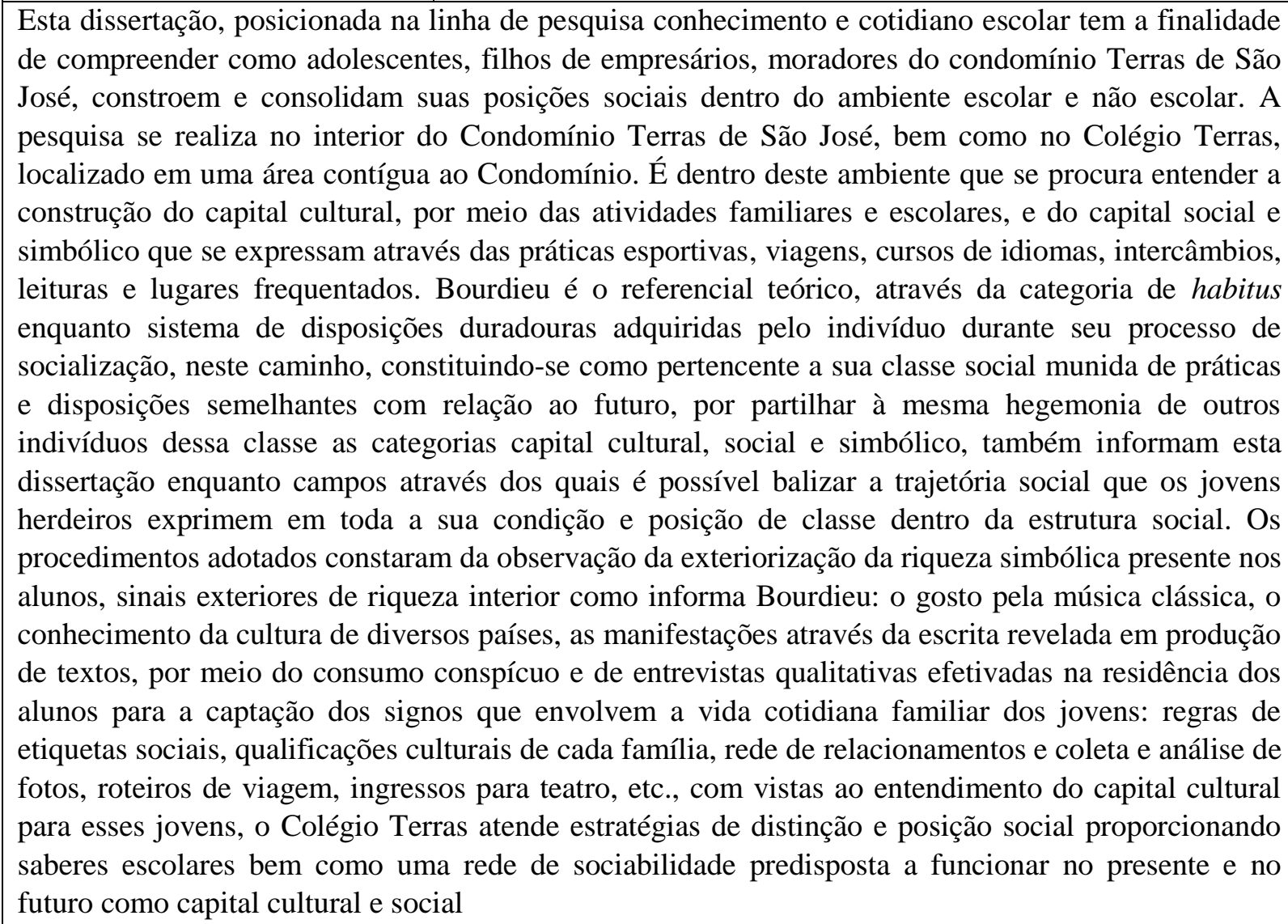 } \\
\hline
\end{tabular}

${ }^{4}$ Fonte: https://sucupira.capes.gov.br/sucupira/ 
$\checkmark$ Quadro 02 - Resumo da dissertação ${ }^{5}$

\begin{tabular}{|c|c|}
\hline Resumo & $\begin{array}{l}\text { OSÓRIO, Paulo Sérgio. Cuidando dos Bem-Nascidos: O Curso } \\
\text { Particular Póvoas Carneiro e a escolarização das elites no } \\
\text { contexto de Urbanização e modernização de Criciúma (1940- } \\
\text { 1962). Criciúma 2008, 133p. (Dissertação de Mestrado) Mestrado } \\
\text { em Educação, Universidade do Extremo Sul Catarinense. }\end{array}$ \\
\hline \multicolumn{2}{|c|}{$\begin{array}{l}\text { Estudo sobre a gênese e o desenvolvimento da escola primária Curso Particular Póvoas Carneiro em } \\
\text { Criciúma entre } 194031962 \text { no contexto de urbanização e modernização da cidade e sua importância } \\
\text { no processo de escolarização de um determinado grupo social, formado por filhos de industriais, de } \\
\text { comerciantes, de proprietários de terras e daqueles profissionais que compunham a emergente classe } \\
\text { média urbana da cidade. A pesquisa procurou verificar o contexto sócio-político-econômico que } \\
\text { produziu as condições necessárias à criação e à implantação da escola primária particular, bem como } \\
\text { se deu o processo de desenvolvimento da escola a partir de sua criação e instalação, em relação ao } \\
\text { contexto sociopolítico e econômico a partir da manifestação de seus agentes: a professora Zulcema, } \\
\text { as professoras da escola e alunos e pais, e explicitar qual o modelo de educação/formação } \\
\text { escolarizada que foi posto em prática pela escola e sua relação com as políticas de modernização } \\
\text { colocadas em prática pelos governos federal e estadual. Para tanto, o estudo se desenvolveu a partir } \\
\text { de uma pesquisa bibliográfica, documental e biográfica que possibilitou o uso de fontes orais, por } \\
\text { meio de entrevistas semiestruturadas. Assim, a pesquisa apontou a necessidade da existência da } \\
\text { escola como resultado do processo desencadeado em Criciúma referente ao crescente } \\
\text { desenvolvimento econômico e as consequentes transformações na vida política, econômica e social, } \\
\text { com a formação de uma classe social que, a partir de então, assume a direção e o controle político- } \\
\text { econômico da cidade. }\end{array}$} \\
\hline
\end{tabular}

${ }^{5}$ Fonte: https://sucupira.capes.gov.br/sucupira/ 
$\checkmark$ Quadro 03 - Resumo da dissertação ${ }^{6}$

\begin{tabular}{|c|c|}
\hline Resumo & $\begin{array}{l}\text { PIRANI, Mario Luiz. Contratos de sucesso escolar: aspectos da } \\
\text { escolarização das elites. Ribeirão Preto, 2010,84p. (Dissertação } \\
\text { de Mestrado) Mestrado em Educação, Centro Universitário Moura } \\
\text { Lacerda. }\end{array}$ \\
\hline \multicolumn{2}{|c|}{$\begin{array}{l}\text { A pesquisa foi desenvolvida no campo da Sociologia da Educação tendo como objetivo central } \\
\text { investigar as estratégias de escolarização das elites e sua reprodução social através da possível } \\
\text { existência de "contratos de sucesso escolar", com um recorte dado à elite acadêmica. Esse fenômeno } \\
\text { foi entendido num primeiro momento, como sendo intencional para a manutenção de status social a a } \\
\text { utilização da escola como campo da reprodução dos ideais hegemônicos. O estudo tomou como base } \\
\text { pesquisas realizadas no Brasil sobre a escolarização de grupos de elites ao longo das duas últimas } \\
\text { décadas. O referencial teórico para a definição e problematização do objeto de estudo foi apropriado } \\
\text { das obras de Almeida \& Nogueira (2002), Bourdieu \& Passeron (1975), Brandão \& Lellis (2003), } \\
\text { Busetto (2006), Lacerda \& Carvalho (2007), Nogueira (1998; 2005) e Young (2007). Neste trabalho, } \\
\text { utilizou-se ainda o conceito de elite de Bobbio et al (1997). O estudo, em particular, concentra-se na } \\
\text { análise sobre a relação das "elites acadêmicas" com a escolarização de seus filhos. A partir de uma } \\
\text { análise pautada em pesquisa documental sobre as propostas da escola e a construção de sua imagem } \\
\text { junto à sociedade, procedemos também à realização de entrevistas semiestruturadas junto a algumas } \\
\text { famílias que possuem filhos matriculados na instituição de ensino médio locus de nossa pesquisa } \\
\text { empírica. Os resultados parciais indicam haver, assim como já aponta a literatura, indícios que } \\
\text { relacionam os objetivos educacionais das famílias com as intenções das instituições de ensino em } \\
\text { manterem não apenas no plano concreto uma posição privilegiada no quesito de aprovação nas } \\
\text { universidades e cursos de mais alto prestígio, mas também consolidar no imaginário social a } \\
\text { existência de uma "excelência" nos serviços educacionais prestados, confirmando-se o ideal de um } \\
\text { "contrato de sucesso escolar" que poderia não só manter, como também reproduzir socialmente a } \\
\text { situação de destaque ocupada, tanto por parte das famílias, como das próprias instituições de ensino } \\
\text { que se voltam à escolarização de grupos sociais da elite. }\end{array}$} \\
\hline
\end{tabular}

${ }^{6}$ Fonte: https://sucupira.capes.gov.br/sucupira/ 
$\checkmark$ Quadro 04 de resumo da dissertação ${ }^{7}$

\begin{tabular}{|l|l|}
\hline \multicolumn{1}{|c|}{ Resumo } & $\begin{array}{l}\text { STAUDT, Luciane. Deficiência intelectual e aprendizagem } \\
\text { escolar: um estudo sobre práticas pedagógicas desenvolvidas } \\
\text { em instituição privada que atende alunos de camadas sociais } \\
\text { elevadas. São Paulo, 2012, 127p. (Dissertação de Mestrado). } \\
\text { Mestrado em Educação: História, Política e Sociedade, Pontifícia } \\
\text { Universidade Católica de São Paulo. }\end{array}$ \\
\hline $\begin{array}{l}\text { Este estudo teve como objetivo geral a identificação e a análise do currículo e do trabalho pedagógico } \\
\text { realizado em uma escola especial destinada a alunos com deficiência intelectual provenientes de } \\
\text { camadas sociais superiores, com a intenção de verificar qual é o trabalho educativo realizado e se tal }\end{array}$ \\
escola apresenta de alguma forma um ensino diferenciado. Para tanto, essa investigação apresenta \\
uma tríplice perspectiva teórica, discutida no primeiro capítulo inicialmente com as contribuições de \\
Apple (1989), Sacristán (1998) e Perrenoud (1993) sobre currículo, organização escolar, práticas e \\
atividades pedagógicas, e posteriormente abordamos questões referentes à definição de deficiência \\
intelectual e sua relação com os processos de escolarização, onde destacamos a contribuição de \\
Vigotski (1989). Por fim procuramos nos apropriar das contribuições de Bourdieu (2009) no que se \\
refere à escolarização e deficiência intelectual. A hipótese inicial desta investigação, de que um \\
currículo de uma escola especial voltada para o atendimento de alunos com deficiência intelectual \\
provenientes das camadas sociais elevadas se diferencia dos voltados à maioria da população e tem \\
por finalidade o desenvolvimento da criança para favorecer uma melhor apropriação do conteúdo \\
escolar, não pode ser comprovada, uma vez que organização escolar e curricular e as práticas \\
pedagógicas, marcadas fundamentalmente pela rotinização das atividades e pela não exploração da \\
manifestação dos alunos, parecem expressar uma perspectiva fixa e imutável dos prejuízos cognitivos \\
apresentados por seu alunado.
\end{tabular}

\footnotetext{
${ }^{7}$ Fonte: https://sucupira.capes.gov.br/sucupira/
} 
$\checkmark$ Quadro 05 de resumo da dissertação ${ }^{8}$

\begin{tabular}{|c|c|}
\hline Resumo & $\begin{array}{l}\text { ZAPPA, Isabella. Ou isto ou aquilo: um estudo exploratório } \\
\text { sobre a escolha da escola de prestígio no Rio de Janeiro Rio de } \\
\text { Janeiro, 2013, 115p. (Dissertação de Mestrado) Departamento de } \\
\text { Educação, Pontifícia Universidade Católica do Rio de Janeiro. }\end{array}$ \\
\hline $\begin{array}{l}\text { Essa dissertação tem } \\
\text { estabelecimentos de er } \\
\text { estudos de Sociologia d } \\
\text { se perceber os critérios } \\
\text { Educação Infantil e de } \\
\text { pesquisa "Contextos in } \\
\text { visão mais ampla do fe } \\
\text { Brandão e Maria Alice } \\
\text { por elas em seus artig } \\
\text { disso, o trabalho tem ce } \\
\text { manutenção e ampliac } \\
\text { contextualização da pes } \\
\text { elites. O segundo disc } \\
\text { entrevistas aos questio } \\
\text { pesquisa e as imagen } \\
\text { momento da escolha. C } \\
\text { explicando seus princip } \\
\text { analisados de maneira } \\
\text { para os setores estudadc }\end{array}$ & $\begin{array}{l}\text { jetivo fazer um estudo exploratório sobre as escolhas de } \\
\text { do no Rio de Janeiro. Está articulada ao SOCED/PUC-Rio nos } \\
\text { sobre a escolarização das elites. Através de entrevistas, procurou- } \\
\text { las utilizadas pelas famílias no momento da escolha da escola de } \\
\text { damental. Também foram utilizados dados do survey SOCED na } \\
\text { e a qualidade de ensino na Educação básica", (2009) para uma } \\
\text { ara a interlocução com o tema foram utilizados os estudos de Zaia } \\
\text { assim como de seus colaboradores e também de estudos indicados } \\
\text { de Ball, Gewirtz e Bowe, Héran e Ballion, dentre outros. Além } \\
\text { ção teórica os estudos de Pierre Bourdieu sobre a habitus, ethos e } \\
\text { ital social através da escola. O primeiro capítulo apresenta a } \\
\text { limitação do objeto nos estudos do SOCED e da escolarização das } \\
\text { tégias metodológicas utilizadas na perspectivada articulação das } \\
\text { survey. O terceiro capítulo apresenta as famílias, sujeitos dessa } \\
\text { s formaram sobre os estabelecimentos de ensino cogitados no } \\
\text { aborda a escolha da escola de Educação Infantil, apresentando e } \\
\text {. No capítulo } 5 \text { os dados do survey do SOCED e as entrevistas são } \\
\text { ra tentar compreender o peso da qualidade do ensino Fundamental }\end{array}$ \\
\hline
\end{tabular}

${ }^{8}$ Fonte: https://sucupira.capes.gov.br/sucupira/ 
Para a análise desse material nós faremos uso de uma das técnicas mais conhecidas da análise de conteúdo, a análise temática. Os textos, objeto de estudo, reúne uma lista de categorias e componentes que necessita ser ordenada. Através da classificação, o objetivo é chegarmos a representações condensadas, de tal maneira que nos possibilite a análise descritiva do conteúdo. Segundo Laurence Bardin (2016: 77), a análise temática consiste na contagem de um ou vários temas ou itens de significação, numa unidade de codificação previamente determinada, de tal modo que diante do texto em análise, a frase é tida como unidade de codificação. A análise temática que procederemos a seguir será conduzida segundo a dimensão das categorias e componentes presentes nos resumos das dissertações, e, através de suas frequências, faremos a análise dos temas em tela.

\section{ANÁLISE TEMÁTICA DOS RESUMOS DAS DISSERTAÇÕES COM O TEMA ESCOLARIZAÇÃO DAS ELITES (FONTE: PLATAFORMA SUCUPIRA/CAPES) - PROCESSO DE CODIFICAÇÃO}

\begin{tabular}{|c|c|c|}
\hline CATEGORIAS & COMPONENTES & FREQUÊNCIA \\
\hline Grupo social & Jovens & 2 \\
\hline \multirow[t]{14}{*}{ Trajetória social } & Adolescentes & 1 \\
\hline & Filhos & 2 \\
\hline & Alunos & 3 \\
\hline & Alunos de elite & 1 \\
\hline & Alunos com deficiência & 1 \\
\hline & intelectual & 1 \\
\hline & Pais & 1 \\
\hline & Famílias & 3 \\
\hline & Herdeiros & 1 \\
\hline & Empresários & 1 \\
\hline & Industriais & 1 \\
\hline & Comerciantes & 1 \\
\hline & Proprietários de terras & 1 \\
\hline & Elite acadêmica & 1 \\
\hline Ambiente & Escola & 4 \\
\hline & Escola primária & 1 \\
\hline & Escola de ensino médio & 1 \\
\hline & Escola privada & 1 \\
\hline & Cidade & 1 \\
\hline Capital cultural (campos) & $\begin{array}{l}\text { Atividades familiares } \\
\text { Atividades escolares }\end{array}$ & 2 \\
\hline $\begin{array}{l}\text { Capital social e simbólico } \\
\text { (campos) }\end{array}$ & $\begin{array}{l}\text { Exteriorização da riqueza } \\
\text { simbólica } \\
\text { Captação dos signos } \\
\text { Habitus } \\
\text { Ethos }\end{array}$ & $\begin{array}{l}2 \\
1 \\
1 \\
1\end{array}$ \\
\hline
\end{tabular}




\begin{tabular}{|c|c|c|}
\hline & $\begin{array}{l}\text { Imaginário social } \\
\text { Práticas esportivas } \\
\text { Viagens } \\
\text { Curso de idiomas } \\
\text { Intercâmbios } \\
\text { Lugares frequentados }\end{array}$ & $\begin{array}{l}1 \\
1 \\
1 \\
1\end{array}$ \\
\hline $\begin{array}{l}\text { Referencial teórico } \\
\text { Autores }\end{array}$ & $\begin{array}{l}\text { Bourdieu } \\
\text { Almeida \& Nogueira } \\
\text { Bourdieu \& Passeron } \\
\text { Brandão e Lellis } \\
\text { Busetto } \\
\text { Lacerda e Carvalho } \\
\text { Nogueira } \\
\text { Young } \\
\text { Bobbio } \\
\text { Apple } \\
\text { Sacristán } \\
\text { Perrenoud } \\
\text { Zaia Brandão } \\
\text { Ball } \\
\text { Gewirtz \& Bowe } \\
\text { Héran \& Ballion }\end{array}$ & $\begin{array}{l}4 \\
1 \\
1 \\
1 \\
1 \\
1 \\
2 \\
1 \\
1 \\
1 \\
1 \\
1 \\
1 \\
1 \\
1 \\
1\end{array}$ \\
\hline Processo de socialização & Rede de sociabilidade & 1 \\
\hline Classe social & $\begin{array}{l}\text { Classe média urbana } \\
\text { Pertencimento }\end{array}$ & 2 \\
\hline Estrutura social & $\begin{array}{l}\text { Condição } \\
\text { Posição } \\
\text { Estratégias de distinção } \\
\text { social }\end{array}$ & $\begin{array}{l}1 \\
1 \\
1\end{array}$ \\
\hline Reprodução social & $\begin{array}{l}\text { Ideais hegemônicos } \\
\text { Ideal de "contrato de sucesso } \\
\text { escolar" }\end{array}$ & $\begin{array}{l}1 \\
2\end{array}$ \\
\hline Métodos e Técnicas & $\begin{array}{l}\text { Observação } \\
\text { Pesquisa bibliográfica, } \\
\text { documental e biográfica. } \\
\text { Fontes orais } \\
\text { Estudo exploratório } \\
\text { Survey } \\
\text { Entrevistas }\end{array}$ & $\begin{array}{l}1 \\
2 \\
2 \\
3\end{array}$ \\
\hline Tempo & $\begin{array}{l}1940-1962 \\
1990-2008 \\
\end{array}$ & 1 \\
\hline Modelo de educação & $\begin{array}{l}\text { Formação escolarizada } \\
\text { Escolarização das elites } \\
\text { Aprendizagem escolar } \\
\text { Práticas pedagógicas } \\
\text { Trabalho educativo }\end{array}$ & $\begin{array}{l}1 \\
2\end{array}$ \\
\hline
\end{tabular}




\begin{tabular}{|l|l|c|}
\hline & Currículo & \\
& Organização escolar & \\
& Ensino diferenciado & \\
& Processos de escolarização & \\
& Educação infantil & \\
& Escolha da escola & \\
\hline Desenvolvimento econômico & $\begin{array}{l}\text { Transformações na vida } \\
\text { política, econômica e social. }\end{array}$ & 1 \\
\hline Sociologia da Educação & Escolarização das elites & 1 \\
\hline
\end{tabular}

Observamos que os estudos sobre o processo de escolarização das elites realizados através dessas dissertações apresentaram um conjunto de categorias sociológicas de forma clara, precisa. No que diz respeito à agência, os grupos sociais em destaque são os alunos em geral e as famílias. Em torno desses dois grupos verificamos estudos sobre os demais atores sociais: jovens, adolescentes, alunos de elite, herdeiros, pais, e os agentes detentores dos meios de produção. E o “cenário onde se desenrola a trama” é a escola por excelência, aquela fincada na urbis.

O referencial teórico predominante nesses estudos é aquele desenvolvido pelo sociólogo francês Pierre Bourdieu, através dos seus conceitos de capital cultural, capital social e simbólico em busca da captação dos signos, da observação e compreensão da exteriorização da riqueza simbólica das atividades escolares e familiares. Além de Bourdieu, a pesquisadora brasileira Maria Alice Nogueira lidera o número de citações, se constituindo numa das precursoras das pesquisas sobre a escolarização das elites no Brasil.

Esse arsenal teórico compartilha com outro tradicionalíssimo: categorias marxistas como classe social, estrutura social, reprodução social, desenvolvimento econômico também são utilizadas para efeito analítico. Sob os auspícios desses conceitos os pesquisadores têm estudado as condições, as posições, as estratégias de distinção social e as ideias hegemônicas.

Os estudos sobre a escolarização das elites têm se desenvolvido no campo disciplinar da Sociologia da Educação, e nesse espaço os mais variados interesses relacionados aos modelos de educação desabrocharam: aprendizagem escolar, práticas pedagógicas, currículo, trabalho educativo, organização escolar, educação infantil, etc. Essas pesquisas desenvolvidas em nosso meio acadêmico tem se utilizado de vários recursos metodológicos e técnica de coleta de dados: a 


\begin{tabular}{|l|l|}
\hline \multicolumn{1}{|c|}{ Resumo } & $\begin{array}{l}\text { FERRARO, Alceu Ravanello. Escolarização } \\
\text { Brasil: articulando as perspectivas de gênero, raça e classe } \\
\text { social. Educação \& Pesquisa (Qualis A1 - ISSN: 1517-9702 - } \\
\text { USP). Vol. 36, N 2, 2010. }\end{array}$ \\
\hline $\begin{array}{l}\text { Este artigo apresenta os resultados de um experimento de articulação das dimensões gênero, raça e classe social } \\
\text { no estudo da dinâmica da escolarização no Brasil, com base nos microdados do Censo Demográfico 2000. O } \\
\text { nível de escolarização é medido por meio da média de anos de estudo realizados com aprovação pela população } \\
\text { de } 10 \text { anos ou mais. O estudo evidencia que essas três dimensões produzem efeitos que não podem ser } \\
\text { simplesmente adicionados, porque obedecem a lógicas distintas. À medida que se passa das gerações mais } \\
\text { velhas para as mais novas, as mulheres passam da condição de inferioridade à de superioridade em termos de } \\
\text { média de anos de estudo, ao passo que a população negra mantém-se em posição de inferioridade, em relação à } \\
\text { população branca, em todas as idades, embora com alguma redução no nível de desigualdade. Por sua vez, as } \\
\text { desigualdades educacionais relacionadas com as diferentes posições na ocupação, tomadas aqui como } \\
\text { indicadores de classe, aparecem como as mais acentuadas, e isso tanto na população masculina como na } \\
\text { feminina, tanto na população branca como na negra. O texto reforça, assim, a importancia e a viabilidade de se } \\
\text { articular, no estudo da escolarização, as dimensões gênero, raça e classe social, como recomendado pela } \\
\text { literatura sobre a questão. }\end{array}$ \\
Palavras-chave: Brasil; Escolarização; Gênero; Raça; Classe social.
\end{tabular}

\begin{tabular}{|l|l|}
\hline Resumo & $\begin{array}{l}\text { POPKEWITZ, Thomas. Ciências da Educação, Escolarização e } \\
\text { Abjeção: diferença e construção da desigualdade. Educação \& } \\
\text { Realidade (Qualis A1 - ISSN: 0100-3143 - UFRGS). Vol. 35, N } \\
3,2010 .\end{array}$ \\
\hline $\begin{array}{l}\text { Neste artigo, traço uma história das ciências dirigidas à escola na } \\
\text { virada do século XX e hoje, focando primordialmente os EUA, exploro os gestos } \\
\text { dúbios de esperança e medo como uma história do presente. Considero os temas de } \\
\text { salvação da educação progressista americana na pedagogia escolar, no cosmopolitismo da criança } \\
\text { que envolve seu gesto de oposto da abjeção e da exclusão nas novas sociologias da comunidade e } \\
\text { da vida da familiar urbana. Retorno aos temas da salvação, da educação e da comunidade urbana } \\
\text { nas reformas contemporâneas num cosmopolitismo do presente que dirige a atenção às qualidades } \\
\text { da criança associadas à aprendizagem ao longo da vida que existe em relação aos medos daquela } \\
\text { criança que vive fora do espaço cultural desse cosmopolitismo. } \\
\text { Palavras-chave: Ciências da Educação, Políticas de Escolarização, Inclusão/Exclusão Social. }\end{array}$ \\
\hline
\end{tabular}




\begin{tabular}{|l|l|}
\hline Resumo & $\begin{array}{l}\text { FERREIRA, Gomes Antônio. A difusão da escola e a afirmação } \\
\text { da sociedade burguesa. Revista Brasileira de História da } \\
\text { Educação (Qualis A1 - ISSN: 1519-5902). Vol. 5, N } \mathrm{N}^{\mathrm{o}} 1,2005 .\end{array}$ \\
\hline
\end{tabular}

A escola deve ser entendida como uma instituição que serve um tempo determinado e que se configura em função das características dum determinado tempo. A sua emergência e difusão resultaram fundamentalmente da relação das elites com a tecnologia, vendo esta tanto como instrumento produtor quanto como capacidade de controlar riqueza e poder. Na generalidade da Europa medieval as escolas estavam nas mãos dos clérigos e localizavam- se em mosteiros, catedrais e em igrejas paroquiais. Mas desde os séculos XII e XIII vemos avançar a criação de escolas laicas nas principais cidades europeias que possuíam uma burguesia importante. Por razões que se cruzam com interesses religiosos, econômicos e nacionalistas, as regiões protestantes da Europa apresentam uma instrução popular mais generalizada que as regiões católicas. Em geral, os povos setentrionais avançaram mais cedo e com mais convicção para a educação popular e mostraram-se mais capazes de atender às necessidades educativas motivadas pelo progresso científico e tecnológico. No entanto, essa não era sequer uma realidade que se visse generalizada nos países europeus nos fins do século XIX e inícios do seguinte. Embora a imposição da escolaridade obrigatória se tivesse expandido de norte a sul da Europa, esta não se cumpriu de igual modo em todos os países. Mas mesmo quando o esforço da escolarização esteve mais em conformidade com o ideário transnacional que promoveu a imposição da escolaridade obrigatória isso nunca significou uma convicção igualitária.

Palavras-Chave: Escolarização; Sociedade Burguesa; Educação Popular; Igreja Católica; Educação.

\begin{tabular}{|l|l|}
\hline Resumo & $\begin{array}{l}\text { CORADINI, Odaci Luiz. Titulação escolar, condição de "elite" e } \\
\text { posição social. Revista Brasileira de Educação (Qualis A1 - ISSN: } \\
1413-2478) . \text { Vol. } 15, N^{\circ} 43,2010 .\end{array}$ \\
\hline
\end{tabular}

O artigo tem como objetivo a apresentação de resultados do exame das relações entre titulação universitária, ocupação profissional e posição social no Brasil das últimas décadas fonte de dados empíricos os microdados dos censos, é confrontada a titulação universitária com os destinos ocupacionais e o rendimento do trabalho principal. Conforme a hipótese geral, como os usos sociais da titulação universitária se inscrevem numa diversidade de mercados e de relações diferenciadas com a estrutura de poder, por um lado ocorre o crescimento da proporção daqueles que têm alguma ocupação de "elite", por outro, a forte polivalência nos usos da titulação universitária resulta também na grande quantidade dos que exercem alguma ocupação com rendimento inferior ao daqueles da categoria ocupacional correspondente ao título. A área de conhecimento tem pouca importância para tanto, ao contrário das possibilidades de usos da titulação em alguma função de comando ou abaixo da respectiva categoria profissional.. Utilizando como

Palavras-chave: titulação universitária e mercado profissional; titulação universitária e grupos dirigentes; titulação escolar e posição social. 


\begin{tabular}{|l|l|}
\hline Resumo & $\begin{array}{l}\text { CARVALHO, Cynthia Paes de. Contextos institucionais e } \\
\text { escolarização: uma hipótese de classificação das escolas da } \\
\text { rede privada de educação básica. Revista Brasileira de Educação } \\
\text { (Qualis A1 - ISSN: 1413-2478). Vol. 11, } \mathrm{N}^{\circ} 31,2006 .\end{array}$ \\
\hline
\end{tabular}

Em interlocução com a literatura da sociologia da educação sobre a transmissão intergeracional do patrimônio cultural nas camadas médias, particularmente no que toca aos investimentos educacionais, foi construída uma tipologia das escolas e das trajetórias escolares da educação básica. A partir de uma hipótese de classificação das escolas da rede privada de ensino no Rio de Janeiro, são descritos os diferentes percursos escolares encontrados e são discutidos alguns resultados da análise dos dados referentes ao grupo estudado. Conclui-se ressaltando o potencial heurístico da caracterização de senhada, no sentido de ampliar a compreensão do conjunto dos estabelecimentos de ensino básico e enriquecer as possibilidades de análise para além da distinção do caráter público ou privado das escolas.

Palavras-chave: escolas; trajetórias; estratégias.

\begin{tabular}{|l|l|}
\hline Resumo & $\begin{array}{l}\text { NOGUEIRA, Maria Alice. Favorecimento econômico e } \\
\text { excelência escolar: um mito em questão. Revista Brasileira de } \\
\text { Educação (Qualis A1 - ISSN: 1413-2478). N }{ }^{\circ} \text { 26, 2004. }\end{array}$ \\
\hline
\end{tabular}

Na pesquisa educacional brasileira ainda carecemos de estudos sobre os processos de escolarização dos jovens originários de famílias privilegiadas do ponto de vista econômico. O presente trabalho propõe-se a incursionar, portanto, em terreno altamente lacunar, apresentando alguns resultados parciais de um estudo realizado, em 2000-2001, com 25 famílias de grandes e médios empresários (as) de Minas Gerais, cujo objetivo principal era conhecer as histórias escolares dos jovens e as estratégias educativas postas em prática por esses pais ao longo desses itinerários. Um corpus de 50 entrevistas, feitas com os jovens e suas mães, foi reunido. Suas conclusões permitem questionar a ideia corrente de que o padrão de excelência escolar é apanágio dos "ricos" ou, em outros termos, de que as elites escolares se compõem de alunos "ricos".

Palavras-chave: trajetórias escolares; estratégias educativas familiares; relação família-escola. 
$\checkmark$ Quadro de resumos dos artigos das revistas "Qualis A2" 10

\begin{tabular}{|l|l|}
\hline Resumo & $\begin{array}{l}\text { PEDROSA, Graziela. Educação diferenciada e trajetórias } \\
\text { profissionais femininas. Tempo Social: revista de Sociologia da } \\
\text { USP (Qualis A2 - ISSN: 0103-2070). Vol. 20, } \mathrm{N}^{\circ} \text { 1, 2008. }\end{array}$ \\
\hline
\end{tabular}

Este artigo tem como objetivo examinar os usos e os efeitos da passagem pelo sistema de ensino, focalizando estratégias desenvolvidas por famílias de dirigentes paulistas para controlar a educação escolar de suas filhas, em uma cidade em acelerado processo de urbanização, crescimento demográfico vertiginoso e de industrialização crescente como era São Paulo nas décadas de 1950 e 1960. Constituíram em objeto de estudo as trajetórias socioprofissionais de um grupo de mulheres, ex-alunas de três escolas católicas da cidade, para interrogar-se sobre a gênese dos investimentos femininos no mundo social. Os procedimentos de pesquisa incluíram uma pesquisa de campo, a aplicação de questionários e a realização de entrevistas biográficas com exprofessoras, diretoras das escolas e ex-alunas. Os resultados sugerem que o investimento diferenciado dessas mulheres sobre a esfera profissional está relacionado com a estrutura de patrimônio das famílias, as formas de estruturar a experiência escolar das meninas e os padrões de alianças matrimoniais realizadas por esse grupo de mulheres.

Palavras-chave: Famílias de elite; Escola privada; Profissionalização feminina.

\begin{tabular}{|l|l|}
\hline Resumo & $\begin{array}{l}\text { PICCIN, Marcos Botton. Acesso a posições de poder pela elite } \\
\text { estancieira gaúcha: trajetórias sociais e investimentos } \\
\text { escolares. Tempo Social: revista de Sociologia da USP (Qualis A2 } \\
- \text { ISSN: 0103-2070). Vol. } 27, \mathrm{~N}^{\circ} 2,2015 .\end{array}$ \\
\hline
\end{tabular}

$\mathrm{O}$ artigo analisa os significados dos investimentos em relações sociais e em títulos escolares da elite estancieira - grande proprietária de terras - no Rio Grande do Sul, entre 1930 e 1980. Ao contrário das principais elites agrárias no país, os estancieiros possuem uma trajetória coletiva de ascensão tanto econômica como política no período em questão. Nesse contexto, tais investimentos foram uma estratégia de aumento do capital simbólico e não uma estratégia para fugir do descenso social e reconverter trajetórias por causa da crise econômica dos domínios fundiários de suas famílias. Nessa investigação se fez uso da observação direta para geração de dados etnográficos, entrevistas e pesquisa documental e genealógica.

Palavras-chave: Elites rurais; Patronato rural; Estancieiros; Rio Grande do Sul.

\footnotetext{
${ }^{10}$ Fonte:

https://sucupira.capes.gov.br/sucupira/public/consultas/coleta/veiculoPublicacaoQualis/listaConsultaGeralPeriodicos.jsf
} 


\section{ANÁLISE TEMÁTICA DOS RESUMOS DOS ARTIGOS PUBLICADOS EM PERIÓDICOS QUALIS 1 E QUALIS 2 COM O TEMA ESCOLARIZAÇÃO DAS ELITES \\ (FONTE: PLATAFORMA SUCUPIRA/CAPES) PROCESSO DE CODIFICAÇÃO}

\begin{tabular}{|c|c|c|}
\hline CATEGORIAS & COMPONENTES & FREQUÊNCIA \\
\hline Grupos sociais & $\begin{array}{l}\text { Elite } \\
\text { Elites acadêmicas } \\
\text { Filhos } \\
\text { Professores universitários } \\
\text { Mulheres } \\
\text { População negra } \\
\text { População branca } \\
\text { Crianças } \\
\text { Famílias } \\
\text { Comunidade } \\
\text { Jovens } \\
\text { Empresários } \\
\text { Elites escolares } \\
\text { Diretoras } \\
\text { Ex-alunas }\end{array}$ & $\begin{array}{l}1 \\
1 \\
1 \\
1 \\
1 \\
1 \\
1 \\
1 \\
4 \\
1 \\
1 \\
1 \\
1 \\
1 \\
1\end{array}$ \\
\hline Referencial teórico & Pierre Bourdieu & 1 \\
\hline $\begin{array}{l}\text { Conceitos } \\
\text { Capital cultural } \\
\text { Classe social } \\
\text { Gênero } \\
\text { Raça }\end{array}$ & $\begin{array}{l}\text { Estratégias educativas } \\
\text { Aumento do capital } \\
\text { simbólico }\end{array}$ & $\begin{array}{l}2 \\
1 \\
1 \\
1 \\
1\end{array}$ \\
\hline Estrutura social & $\begin{array}{l}\text { Desigualdades educacionais } \\
\text { Riqueza } \\
\text { Poder } \\
\text { Posição social } \\
\text { Ocupação profissional } \\
\text { Estrutura patrimonial }\end{array}$ & $\begin{array}{l}1 \\
1 \\
1 \\
1 \\
1 \\
1\end{array}$ \\
\hline Escolarização & $\begin{array}{l}\text { Dinâmica da escolarização } \\
\text { Educação } \\
\text { Aprendizagem } \\
\text { Educação popular } \\
\text { Escolaridade } \\
\text { Titulação universitária } \\
\text { Investimentos educacionais } \\
\text { Tipologias das escolas } \\
\text { Ensino básico } \\
\text { Trajetórias escolares } \\
\text { Sistema de ensino }\end{array}$ & $\begin{array}{l}3 \\
1 \\
1 \\
1 \\
1 \\
1 \\
1 \\
1 \\
1 \\
1 \\
1 \\
1 \\
1\end{array}$ \\
\hline Ambiente & Escolas & 3 \\
\hline
\end{tabular}




\begin{tabular}{|l|l|c|}
\hline & $\begin{array}{l}\text { Urbis } \\
\text { Espaço cultural } \\
\text { Processo de urbanização }\end{array}$ & 1 \\
\hline Sociologia da Educação & $\begin{array}{l}\text { Transmissão intergeracional } \\
\text { do patrimônio cultural das } \\
\text { camadas médias }\end{array}$ & 1 \\
\hline Métodos e técnicas & $\begin{array}{l}\text { Pesquisa de campo } \\
\text { Questionários } \\
\text { Entrevistas }\end{array}$ & 1 \\
& Pesquisa documental & 1 \\
\hline
\end{tabular}

O uso da análise temática permite ao estudioso utilizar o recurso da comparação. Ficamos inclinados a verificar se o conjunto de categorias utilizadas nas dissertações acima também está presente nos artigos que encontramos nos periódicos da Plataforma Sucupira - Capes. No que diz respeito aos atores sociais percebe-se uma incidência maior sobre o grupo familiar, porém, os demais agentes coincidem com aqueles "vistos" nos estudos anteriores. O diferencial é que a pesquisa foi realizada abrangendo outros grupos sociais: os negros, as diretoras das escolas e excontinuou alunas de educandários. $\mathrm{O}$ ambiente sobre o qual os estudos se debruçaram continuou sendo a cidade, e, especificamente a escola.

A sociologia de Pierre Bourdieu continuou predominando como referencial teórico: praticamente quase todos os artigos aqui reunidos têm o sociólogo francês como referência teórica.

Outras categorias aparecem na fronteira com a ciência econômica: riqueza e estrutura patrimonial. Entretanto, quando se fala escolarização o leque categorial ampliou-se: dinâmica da escolarização, processo de aprendizagem, educação popular, escolaridade, investimentos educacionais, tipologias das escolas, ensino básico, sistema de ensino, trajetórias escolares, etc.

A área de estudos onde as pesquisas se desenvolveram permaneceu o mesmo: a Sociologia da Educação. As técnicas de pesquisa prevalecentes nesses trabalhos compreenderam o uso de pesquisa documental, observação direta, entrevistas e aplicação de questionários. 


\section{Considerações}

Mesmo trabalhando com uma quantidade significativa de periódicos e no intervalo de tempo igualmente considerável, esse levantamento encontrou pouquíssimo material a respeito da temática "Escolarização das Elites". Diante dessa constatação ficou evidente a necessidade de darmos continuidade à pesquisa a fim de verificar se esse problema de escassez de produções é resultado da escolha de área do conhecimento ou se ela indica uma lacuna no campo de pesquisa sobre as elites no Brasil. Esse questionamento decorrente de primeiro levantamento é o próximo passo da nossa investigação.

\section{Referências}

ALFREDO, Mauricio. A socialização dos herdeiros: as trajetórias social e escolar de jovens pretendentes a dirigentes. Sorocaba 2005, 115p. (Dissertação de Mestrado) Mestrado e Educação, Universidade de Sorocaba.

ALMEIDA, Maria F. e NOGUEIRA, Maria Alice (Orgs.). A escolarização das elites. Um panorama internacional da pesquisa. $2^{\mathrm{a}}$ Ed. Petrópolis: Editora: Vozes, 2003.

BARDIN, Laurence. Análise de conteúdo. São Paulo: Edições 70, 2016.

CARVALHO, Cynthia Paes de. Contextos institucionais e escolarização: uma hipótese de classificação das escolas da rede privada de educação básica. Revista Brasileira de Educação. Vol.11, n.31, pp.155-166. 2006.

CORADINI, Odaci Luiz. Titulação escolar, condição de "elite" e posição social. Revista Brasileira de Educação. Vol.15, n.43, pp.45-69. 2010.

FERRARO, Alceu Ravanello. Escolarização no Brasil: articulando as perspectivas de gênero, raça e classe social. Educação e Pesquisa. Vol.36, n.2, pp.505-526. 2010. 
FERREIRA, Gomes Antônio. A difusão da escola e a afirmação da sociedade burguesa. Revista Brasileira de História da Educação (ISSN: 1519-5902). Vol. 5, № 1, 2005.

MONTEIRO, José Marciano. "O papel da escola na formação dos herdeiros” in MONTEIRO, José Marciano. A política como negócio de família. Para uma sociologia política das elites e do poder político familiar. São Paulo: LiberArs, 2017.

NOGUEIRA, Maria Alice. Favorecimento econômico e excelência escolar: um mito em questão. Revista Brasileira de Educação. N.26, pp.133-144. 2004.

OSÓRIO, Paulo Sérgio. Cuidando dos Bem-Nascidos: O Curso Particular Póvoas Carneiro e a escolarização das elites no contexto de Urbanização e modernização de Criciúma (1940-1962). Criciúma 2008, 133p. (Dissertação de Mestrado) Mestrado em Educação, Universidade do Extremo Sul Catarinense.

PEROSA, Graziela. Educação diferenciada e trajetórias profissionais femininas. Tempo Social. Revista de Sociologia da USP. Vol.20, n.1, pp.51-68. 2008.

PICCIN, Marcos Botton. Acesso a posições de poder pela elite estancieira gaúcha: trajetórias sociais e investimentos escolares. Tempo Social. Revista de Sociologia da USP. Vol.27, n.2, pp.305-328. 2015.

PIRANI, Mario Luiz. Contratos de sucesso escolar: aspectos da escolarização das elites. Ribeirão Preto, 2010,84p. (Dissertação de Mestrado) Mestrado em Educação, Centro Universitário Moura Lacerda.

POPKEWITZ, Thomas. Ciências da Educação, Escolarização e Abjeção: diferença e construção da desigualdade. Educação \& Realidade (ISSN: 0100-3143 - UFRGS). Vol. 35, N 3, 2010 .

STAUDT, Luciane. Deficiência intelectual e aprendizagem escolar: um estudo sobre práticas pedagógicas desenvolvidas em instituição privada que atende alunos de camadas sociais elevadas. São Paulo, 2012, 127p. (Dissertação de Mestrado). Mestrado em Educação: História, Política e Sociedade, Pontifícia Universidade Católica de São Paulo. 
ZAIA, Brandão; LELLIS, Isabel. Elites Acadêmicas e Escolarização Dos Filhos. Revista Educação \& Sociedade (ISSN: 1678-4626 - UNICAMP). Vol. 24, Nº 83, 2003.

ZAPPA, Isabella. Ou isto ou aquilo: um estudo exploratório sobre a escolha da escola de prestígio no Rio de Janeiro Rio de Janeiro, 2013, 115p. (Dissertação de Mestrado) Departamento de Educação, Pontifícia Universidade Católica do Rio de Janeiro. 